\title{
Hereditary Tyrosinemia Type 1-A Rare Disease with Typical Radiological Features: Case Report and Review of Literature
}

\author{
Somesh Singh ${ }^{1} \quad$ Rana Vishwadeep Mall $^{1}$ Pragya Chaturvedi ${ }^{1}$ Rajnikant R. Yadav ${ }^{1}$ \\ ${ }^{1}$ Department of Radiodiagnosis, Sanjay Gandhi Postgraduate \\ Institute of Medical Sciences, Lucknow, India

\begin{abstract}
Address for correspondence Somesh Singh, MBBS, MD, Department of Radiodiagnosis, Sanjay Gandhi Postgraduate Institute of Medical Sciences, Lucknow 226014, India (e-mail: someshsingh88@gmail.com).
\end{abstract}

J Gastrointestinal Abdominal Radiol ISGAR:2020;3(suppl S1):S58-S64

\begin{abstract}
Hereditary tyrosinemia type 1 is one of the many inborn errors of metabolism associated with tyrosine catabolism. It is a rare disease with its incidence or prevalence in India unknown. The cascading alternate metabolism results in characteristic injury

Keywords

- hepatocellular carcinoma

- hereditary tyrosinemia type 1

- imaging

- succinylacetoacetate patterns to the liver, kidneys, and the central nervous system, with resultant classical radiological findings. Identifying this constellation of imaging features by a radiologist may help in arriving at a diagnosis and help referring physicians in performing appropriate biochemical tests and instituting early treatment. These usually present with chronic liver failure and are extensively evaluated for other causes of liver failure. We present a case type 1 hereditary tyrosinemia with characteristic radiological features and highlight its pathophysiology to understand the basis of these imaging findings.
\end{abstract}

\section{Introduction}

Many inborn errors of metabolism are known to be associated with tyrosine catabolism. Hereditary tyrosinemia type 1 is caused by deficiency of enzyme fumarylacetoacetate hydrolase (FAH). It is inherited in an autosomal recessive pattern with a global incidence of about 1 in 100,000. ${ }^{1}$ Its incidence or prevalence in the Indian subcontinent is not documented.

Its various clinicoradiological manifestations are due to accumulation of fumarylacetoacetate and succinylacetone which mainly affect the liver and kidneys and, to some extent, the central nervous system. Involvement of other organ systems has also been described. ${ }^{2}$ It has a varied spectrum of clinical presentation but may have a relatively constant spectrum of imaging findings.

\section{Clinical Presentation}

A 19-month-old girl was referred to our center for further evaluation for chronic liver disease. She was born to a nonconsanguineous couple with full-term normal vaginal delivery. No history of yellowish discoloration of eyes and skin or passage of high-colored urine was present. There was history of global developmental delay of motor skills. She was immunized adequately for age. She has an elder healthy brother of 12 years of age. She was evaluated elsewhere and an ultrasound of abdomen showed multiple hypoechoic liver lesions. There was no ascites. Portal vein was patent. Her liver function tests were deranged. She was then referred with provisional diagnosis of chronic liver disease with multiple hepatic space occupying lesions for evaluation and management.

\section{Examination}

On examination, the patient weighed $9.6 \mathrm{~kg}$ (10th percentile) with a height of $80 \mathrm{~cm}$ (50th percentile). Mild icterus was present with no pallor, cyanosis, lymphadenopathy, or edema. Clinical signs of rickets (widened bilateral wrists, double malleoli, bowing of legs, etc.) were present. The liver was palpable $4 \mathrm{~cm}$ below the costal margin with nodularity. No splenomegaly was present.

\section{Blood Investigations}

Blood investigations of the child have been summarized in - Table 1. Blood tests revealed deranged liver function

(c) 2020. Indian Society of Gastrointestinal and Abdominal Radiology. This is an open access article published by Thieme under the terms of the Creative Commons Attribution-NonDerivative-NonCommercial-License, permitting copying and reproduction so long as the original work is given appropriate credit. Contents may not be used for commercial purposes, or adapted, remixed, transformed or built upon. (https://creativecommons.org/licenses/by-nc-nd/4.0/)

Thieme Medical and Scientific Publishers Pvt. Ltd., A-12, 2nd Floor, Sector 2, Noida-201301 UP, India 
Table 1 Blood and serological workup of our patient

\begin{tabular}{|c|c|c|}
\hline Parameter & Value & Normal range ${ }^{17}$ \\
\hline \multicolumn{3}{|l|}{ Liver function tests } \\
\hline Total bilirubin & $3.23 \mathrm{mg} / \mathrm{dL}$ & $0.2-1.2 \mathrm{mg} / \mathrm{dL}$ \\
\hline Conjugated bilirubin & $1.84 \mathrm{mg} / \mathrm{dL}$ & $0.1-0.3 \mathrm{mg} / \mathrm{dL}$ \\
\hline Total serum proteins & $4.76 \mathrm{mg} / \mathrm{dL}$ & $6.0-8.0 \mathrm{mg} / \mathrm{dL}$ \\
\hline Serum albumin & $3.01 \mathrm{mg} / \mathrm{dL}$ & $3.8-5.5 \mathrm{mg} / \mathrm{dL}$ \\
\hline Serum SGOT & $77 \mathrm{IU} / \mathrm{L}$ & $8.0-40.0 \mathrm{IU} / \mathrm{L}$ \\
\hline Serum SGPT & $60 \mathrm{IU} / \mathrm{L}$ & $8.0-40.0 \mathrm{IU} / \mathrm{L}$ \\
\hline $\begin{array}{l}\text { Serum alkaline } \\
\text { phosphatase }\end{array}$ & $5870 \mathrm{IU} / \mathrm{L}$ & $60.0-270.0 \mathrm{IU} / \mathrm{L}$ \\
\hline \multicolumn{3}{|l|}{ Renal function tests } \\
\hline Serum creatinine & $0.5 \mathrm{mg} / \mathrm{dL}$ & $0.5-1.3 \mathrm{mg} / \mathrm{dL}$ \\
\hline \multicolumn{3}{|l|}{ Serum electrolytes } \\
\hline Serum sodium & $140 \mathrm{mmol} / \mathrm{L}$ & $136-145 \mathrm{mmol} / \mathrm{L}$ \\
\hline Serum potassium & $3.5 \mathrm{mmol} / \mathrm{L}$ & $3.8-5.5 \mathrm{mmol} / \mathrm{L}$ \\
\hline Serum magnesium & $1.8 \mathrm{mg} / \mathrm{L}$ & $1.7-2.4 \mathrm{mg} / \mathrm{L}$ \\
\hline Serum calcium & $7.9 \mathrm{mg} / \mathrm{L}$ & $9.0-11.0 \mathrm{mg} / \mathrm{L}$ \\
\hline Serum phosphorus & $2.0 \mathrm{mg} / \mathrm{L}$ & $2.3-4.7 \mathrm{mg} / \mathrm{L}$ \\
\hline \multicolumn{3}{|l|}{ Coagulation profile } \\
\hline Prothrombin time & $41.3 \mathrm{~s}$ & $9.5-13.5 \mathrm{~s}$ \\
\hline INR & 3.2 & $<1.3$ \\
\hline \multicolumn{3}{|l|}{ Urinalysis } \\
\hline Proteins & Trace & \\
\hline $\begin{array}{l}24 \text { hour urine } \\
\text { phosphorus }\end{array}$ & $51.2 \mathrm{mg} / \mathrm{L}$ & $29-42 \mathrm{mg} / \mathrm{L}$ \\
\hline \multicolumn{3}{|l|}{ Hemogram } \\
\hline Hemoglobin & $10.4 \mathrm{~g} / \mathrm{dL}$ & $10.0-14.0 \mathrm{mg} / \mathrm{mL}$ \\
\hline Platelets & $168,000 / \mathrm{mL}$ & $\begin{array}{l}150,000-400,000 / \\
\mathrm{mL}\end{array}$ \\
\hline Total leucocyte count & $15,800 / \mathrm{mL}$ & $4,000-11,000 / \mathrm{mL}$ \\
\hline \multicolumn{3}{|l|}{ Viral markers } \\
\hline HbsAg & Nonreactive & \\
\hline INR & Nonreactive & \\
\hline \multicolumn{3}{|l|}{ Tumour markers } \\
\hline Alfa-fetoprotein & $32,825 \mathrm{ng} / \mathrm{mL}$ & $0.0-8.5 \mathrm{ng} / \mathrm{mL}$ \\
\hline
\end{tabular}

Abbreviations: AFP, alfafetoprotein; HbsAg, Hepatitis B Surface Antigen; SGOT, serum glutamic oxaloacetic transaminase; SGPT, serum glutamic pyruvic transaminase.

with deranged serum glutamic oxaloacetic transaminase (SGOT), serum glutamic pyruvic transaminase (SGPT), and alkaline phosphatase (ALP) levels. She had hypoproteinemia and hypoalbuminemia. Her coagulation profile was severely deranged, not correctable with vitamin $\mathrm{K}$ injections. Both conjugated and unconjugated bilirubin levels were raised. Viral markers for hepatitis B and C were nonreactive. Serum creatinine was normal. Urine examination revealed trace proteinuria and phosphaturia. Serum electrolytes profile revealed hypophosphatemia and hypocalcaemia. Serum alfafetoprotein (AFP) levels were significantly raised $(\sim 32,000 \mathrm{ng} / \mathrm{mL})$. Based on these findings, provisional diagnosis of chronic liver failure with hypophasphatemic rickets was considered.

\section{Imaging}

Radiographs of bilateral wrists and knees showed typical fraying, splaying, and cupping of bilateral distal femoral, radial, and ulnar metaphyses, consistent with rickets ( - Fig. $\mathbf{1}$ ).

In view of multiple space-occupying lesions on ultrasound performed elsewhere, a triple-phase contrast-enhanced computed tomography (CT) scan of abdomen and pelvis was performed on a 64-slice multidetector CT scanner (Philips Ingenuity, Philips Healthcare, Cleveland, Ohio, United States) after administration of $60 \mathrm{~mL}$ intravenous nonionic contrast medium with automated exposure control. Contrast medium used was iohexol of strength $300 \mathrm{mg} / \mathrm{mL}$ (Omnipaque, GE Healthcare, Marlborough, United States).

Noncontrast sections in bone windows again showed changes of rickets ( - Fig. 2). Additionally, liver was shrunken and studded with multiple rounded and well-defined rounded nodules with resultant nodular surface $(\boldsymbol{- F i g}$. 3 ). These nodules were hyperdense on noncontrast study (approximate HU (Hounsefield Unit) of 54) and showed no significant enhancement on subsequent arterial, equilibrium, and hepatic phases. These were likely to represent regenerating nodules. Additionally, a small isodense, ill-defined observation was seen in segment IVb of liver (-Fig. 4). It showed nodular nonrim arterial phase hyperenhancement, showing subsequent washout and appearing isodense to normal liver parenchyma on equilibrium and hepatic phases. No capsule was discernible on delayed phase. This was suspicious for hepatocellular carcinoma (HCC). This correlated with patients' high AFP levels. There was no thrombosis of the portal vein and its branches and of the hepatic veins. There was no ascites. Additionally, both kidneys were enlarged with maintained corticomedullary differentiation on venous phase ( - Fig. 5). Both kidneys measured $10 \mathrm{~cm}$ in length (normal up to $6.7 \mathrm{~cm}$ for this $\mathrm{age}^{3}$ ). No features to suggest nephrocalcinosis were noted on plain CT. A bedside sonography performed after the CT scan did not show any features of nephrocalcinosis.

\section{Diagnosis}

With constellation of findings of chronic liver failure with focus of suspicious HCC, bilateral renomegaly, and hypophasphatemic rickets, a possibility of hereditary tyrosinemia type 1 was considered. Patient's urine was positive for succinylacetone levels, confirming the diagnosis. Our patient did not have "boiled cabbage"|"rotten mushroom" odor urine as reported in literature for patients with hereditary tyrosinemia type $1 .^{4}$

\section{Treatment, Outcome, and Follow-up}

Patient was referred to a specialist center to institute nitisinone (NTBC) treatment and to work up for hepatic transplantation. Meanwhile, the family was advised on diet with restricted phenylalanine and tyrosine intake. Genetic counseling of family was also done. 


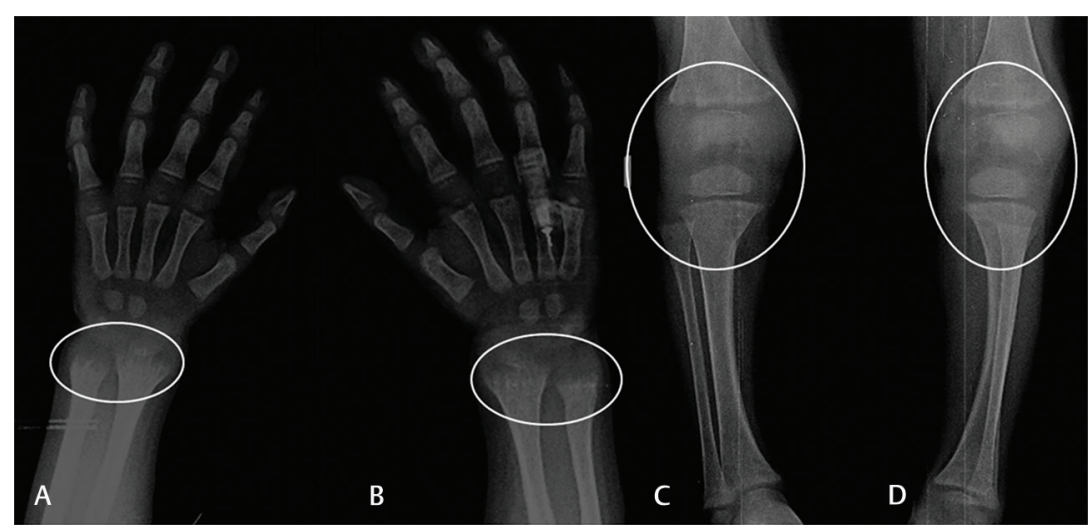

Fig. 1 Frontal radiographs of both wrists and legs show typical features of rickets. (A, B) Cupping (concavity), fraying (indistinct margins), and splaying (widening) of distal metaphyses of radius and ulna bilaterally (encircled). (C, D) Similar changes involving the lower end of bilateral femora and upper ends of tibia and fibula.

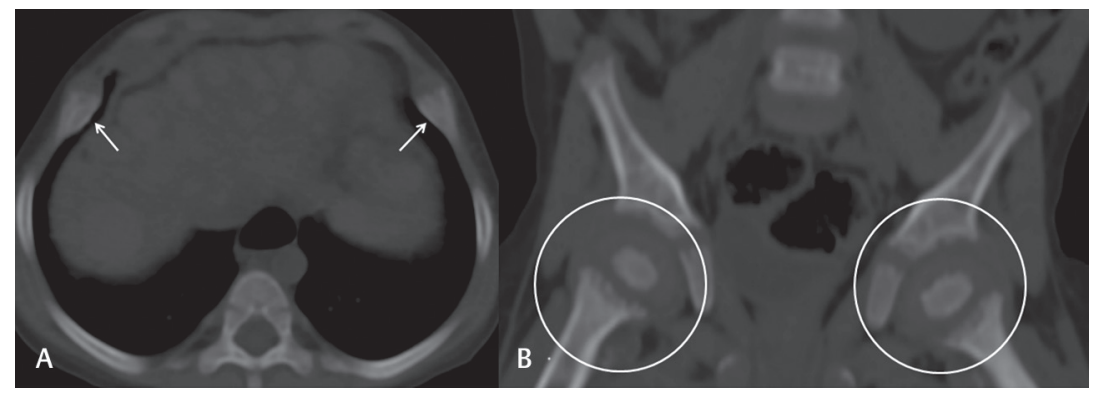

Fig. 2 Axial CT cuts in bone window through the lower thorax; bilateral widening of anterior ribs (arrows) at costochondral junctions (A). Cupping, fraying, and splaying of bilateral upper femora metaphyses (encircled) are shown in coronal CT in bone window of pelvis (B). Findings are typical of rickets.

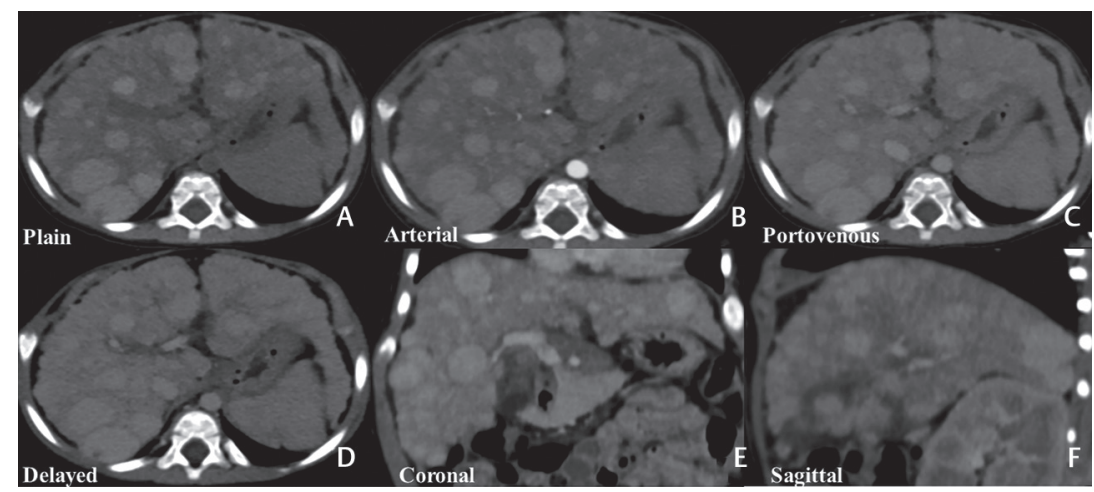

Fig. 3 Sequential axial CT scan through the liver at same level. Axial noncontrast (A), arterial phase (B), equilibrium phase (C), and hepatic phase (D) images are shown. They show multiple well-defined rounded hyperdense lesions scattered in both lobes of the liver showing no significant enhancement on sequential imaging, suggestive of regenerative nodules. Hyperdensity on plain scan may suggest their siderotic nature. Many nodules are greater than $3 \mathrm{~cm}$ in diameter, suggestive of macronodules. Coronal (E) and sagittal (F) sections demonstrate shrunken liver with diffuse surface nodularity secondary to regenerative nodules.

\section{Discussion}

Tyrosinemia is a rare inborn error of metabolism inherited in an autosomal recessive manner ${ }^{5}$ which predominantly caused affliction of liver and kidneys but also involves central nervous system. ${ }^{6}$ Few case reports causing reversible hypertrophic cardiomyopathy have also been described. ${ }^{2}$ - Fig. 6 demonstrates a schema of normal tyrosine catabolism and broad overview of metabolic pathway in hereditary tyrosinemia type 1. - Fig. 7 shows metabolic pathway of tyrosine with various clinical manifestations that occur due to specific enzymatic dysfunction.

The enzyme whose deficiency/dysfunction leads to this disease is fumarylacetoacetate hydrolase. This enzyme is involved in terminal step of tyrosine catabolism, cleaving fumarylacetoacetate to fumarate and acetoacetate. There is, hence, accumulation of fumarylacetoacetate which is the main culprit of the disease. It is rapidly metabolized in the cytoplasm of hepatocytes and renal tubular cells and, hence, is not detected in serum or urine of patients. It is a strong 


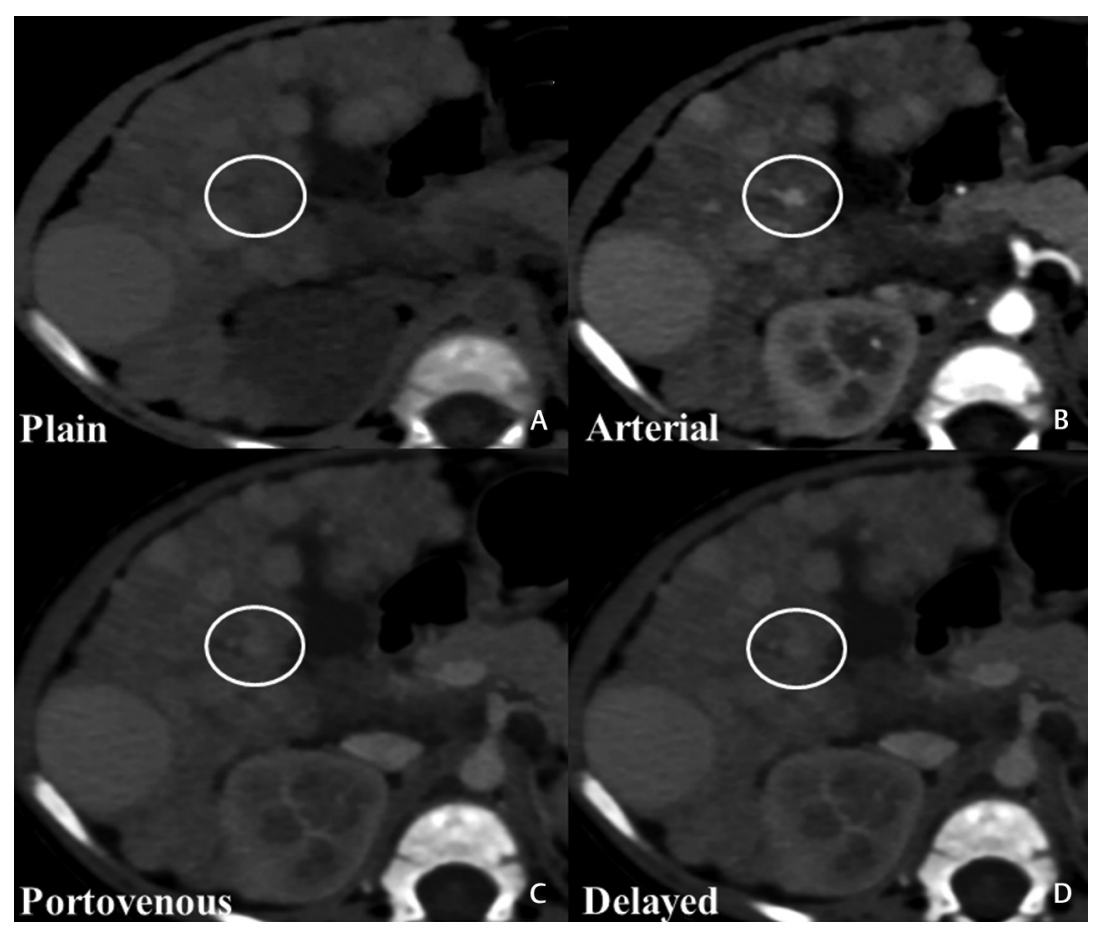

Fig. 4 Sequential axial CT scan through the liver at a lower level. Axial noncontrast (A), arterial phase (B), equilibrium phase (C), and hepatic phase (D) images are shown. A small isodense, ill-defined observation seen in segment IVb of the liver (encircled). It shows nodular nonrim arterial phase hyperenhancement, showing subsequent washout and appearing isodense to the normal liver parenchyma on equilibrium and hepatic phases. No capsule was discernible on delayed phase: suspicious for hepatocellular carcinoma (HCC).

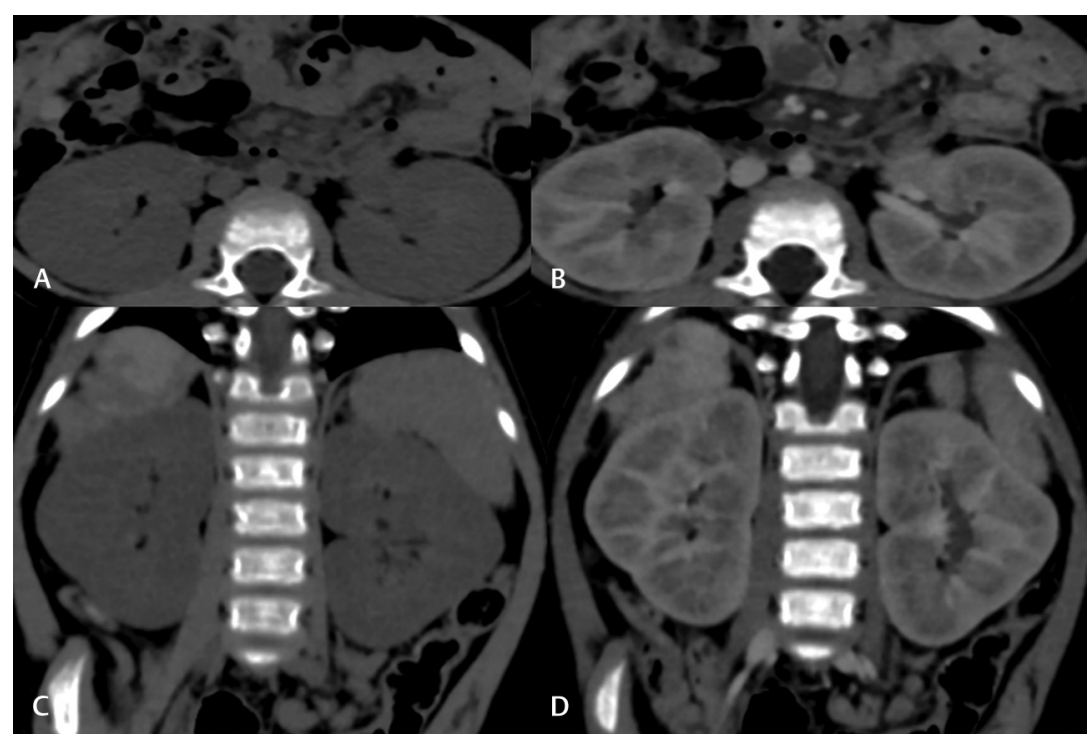

Fig. 5 Plain axial (A) and coronal (C) CT with postcontrast counterparts (B, D). These demonstrate diffuse enlargement of both the kidneys (extending across 5 vertebrae) with preservation of corticomedullary differentiation. No hyperdensities seen on noncontrast scans to suggest nephrocalcinosis.

alkylating agent and caused oxidative damage, resulting in damage to hepatocytes and renal tubal cells. It is also a known mutagen, explaining the high incidence of hepatocellular carcinoma in patients with hereditary tyrosinemia type 1.78 The effect of these is that it leads to chronic liver failure, hepatocellular carcinoma, and renal tubular injury. Renal tubular injury results in aminoaciduria, glycosuria, and phosphaturia. This results in renal tubular acidosis with hypophostemia and hypoproteinemia, leading to Fanconi syndrome and hypophosphatemic rickets. In addition, there is clinical presentation of chronic renal failure, morphological presentation of renomegaly and nephrocalcinosis, and histopathological presentation of glomeruloscleorsis. Accumulated fumarylacetoacetate is rapidly metabolized to succinylacetoacetate by yet unidentified enzymes. Succinylacetoacetate is rapidly decarboxylated to succinylacetone.

It is succinylacetone which is found in increased levels in serum and excreted in urine and detection of this forms 

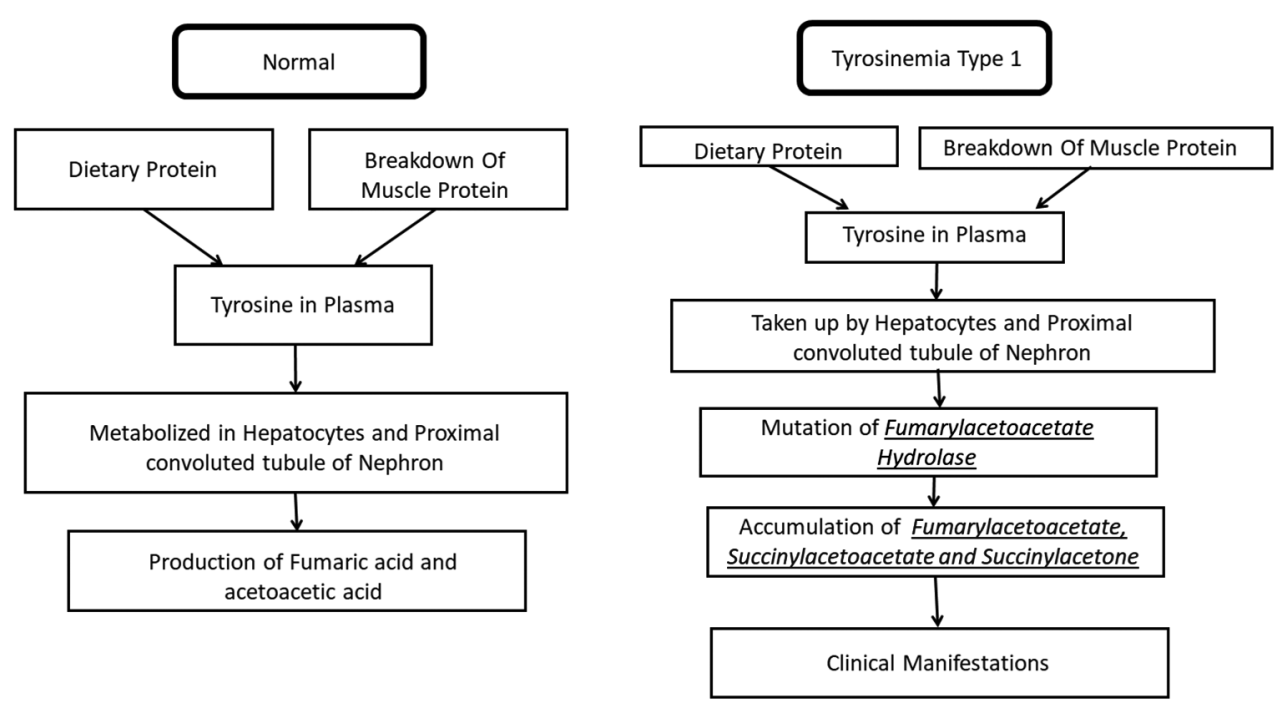

Fig. 6 Overview of normal tyrosine catabolism (on left) with basic pathophysiology of hereditary tyrosinemia type 1 .

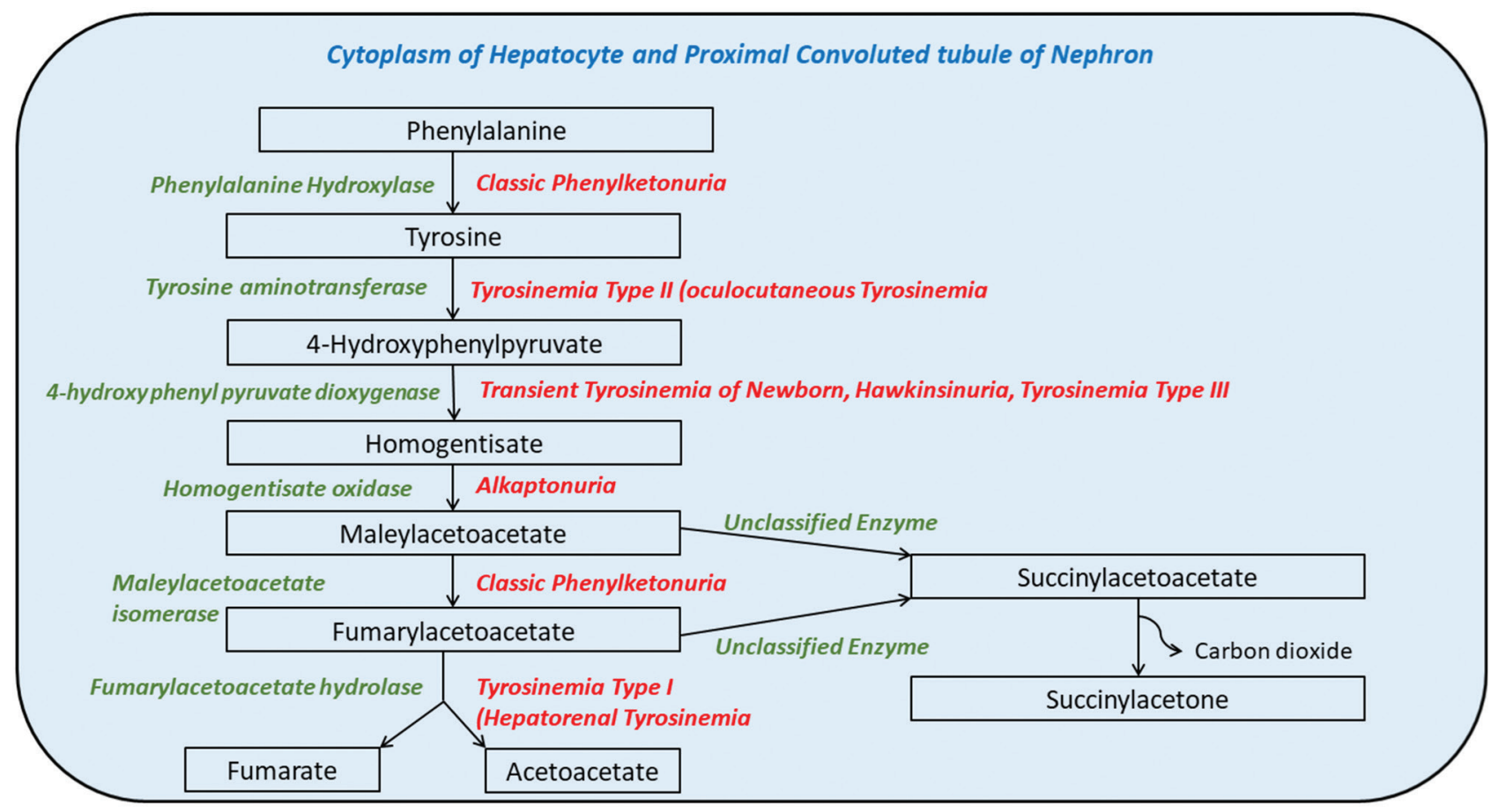

Fig. 7 Tyrosine catabolism and various defects of tyrosine metabolism.

the basis of diagnosis of hereditary tyrosinemia type 1. Excretion into urine causes what is described as "boiled cabbage" or "rotten mushroom" smell of urine. Our patient did not demonstrate this aspect. In addition, succinylacetone enters mitochondria of renal tubular cells and inhibits Kreb's cycle, further aggravating tubular injury. It also inhibits aminolevulinic acid dehydratase, which is precursor of heme synthesis. This forms the basis of porphyria-like episodes documented in these patients. ${ }^{9}$ The pathophysiology has been illustrated as a flowchart depicted in -Fig. 8.

The presentation may be acute, subacute, or chronic based on age at presentation. ${ }^{10}$ Acute presentation occurs in children
$<6$ months of age, subacute in those presenting between 6 and 12 months of age, and chronic in patients presenting after 1 year of age. Majority of the patients present with acute form. ${ }^{5}$ Liver is the most common organ involved. ${ }^{11}$ Acute form usually presents with acute liver failure. Subacute form presents as chronic liver disease and/or renal failure. Chronic form can show varied manifestations. Some patients present after 2 years with isolated features of coagulopathy, liver/renal/neurological dysfunction. Some patients may present with hepatocellular carcinoma as a presenting feature. ${ }^{12}$ Neurological features include porphyria-like syndromes (painful episodes involving extremities or abdomen), hypertension, and polyneuropathy. Some case reports have reported high signal intensity of globus 


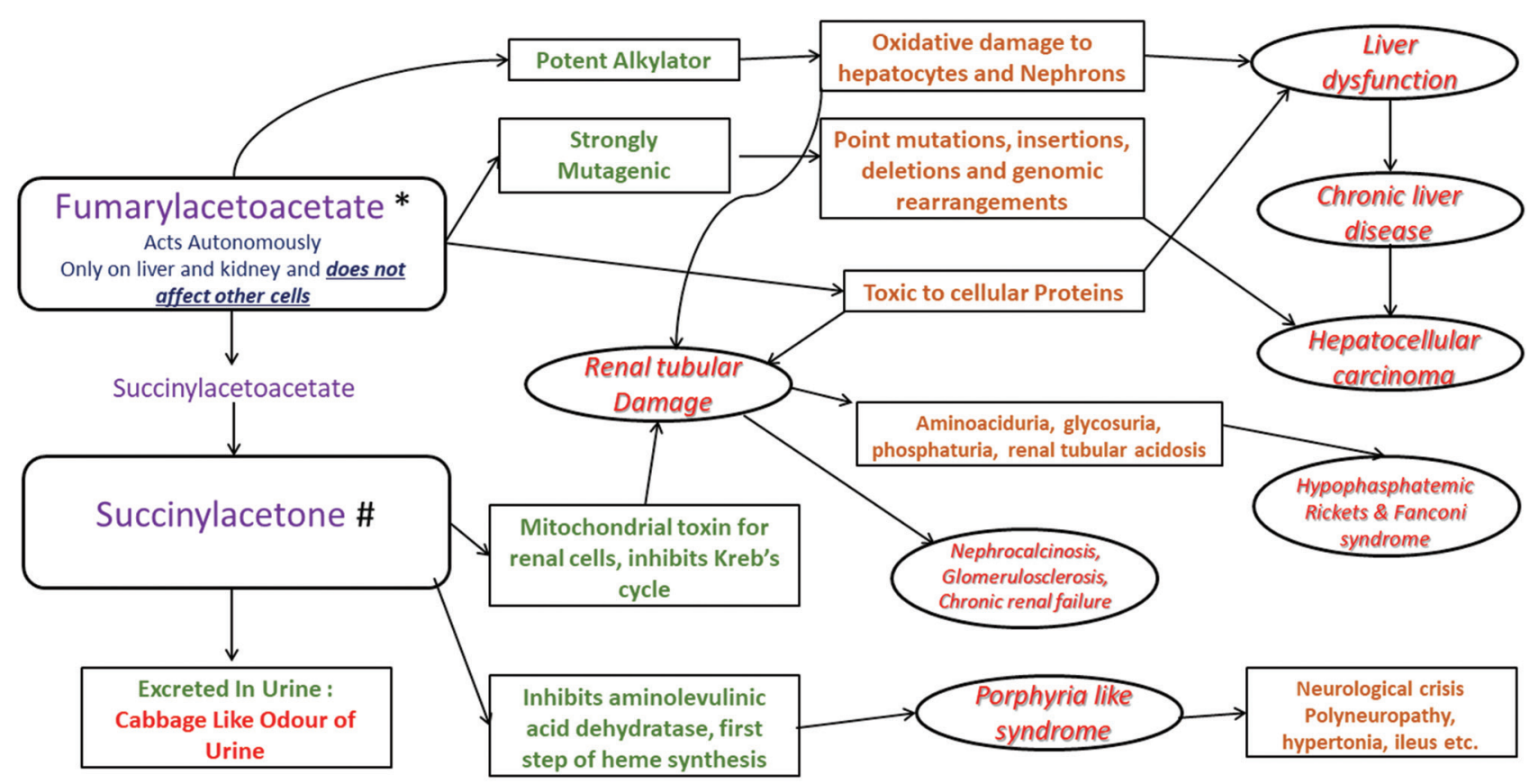

Fig. 8 Pathophysiology of hereditary tyrosinemia type I and basis of various clinical manifestations.

pallidi on T2-weighted magnetic resonance imaging (MRI). ${ }^{13}$ We did not perform any imaging of brain for our patient as she had no neurological symptoms. Some case reports of pancreatic involvement have also been described. ${ }^{14}$

In summary, the various systemic manifestations include the following:

Hepatobiliary system: Acute and chronic liver failure, coagulopathy, hepatocellular carcinoma.

Renal: Aminoaciduria, glycosuria, and phosphaturia-renal tubular acidosis with hypophostemia and hypoproteinemia (Fanconi syndrome), and hypophosphatemic rickets; "boiled cabbage" or "rotten mushroom" smell of urine; renomegaly and nephrocalcinosis.

\section{Skeletal system: Rickets.}

Central nervous system: Porphyria-like episodes, hypertension, polyneuropathy, high signal intensity of globus pallidi on T2-weighted MRI.

Others: Reversible hypertrophic cardiomyopathy.

Elevated succinylacetone levels form the basis of neonatal screening. While tyrosine may be elevated in other errors of tyrosine catabolism, elevated succinylacetone levels are specific for hereditary type 1 tyrosinemia. Hence, serum succinylacetone levels are recommended neonatal screening tool. ${ }^{5}$ Presence of succinylacetone in urine is confirmatory. ${ }^{5}$ Molecular testing for fumarylacetoacetate is recommended for confirmation as well. A genetic counseling and screening of sibling(s) is recommended.

Early detection allows for early institution of management which includes dietary restriction of food rich in phenylalanine and tyrosine. 2-[2-nitro4-trifluoromethylbenzoyl]-1, 3-cyclohexanedione (NTBC, nitisinone) is the treatment of choice for medical management. It inhibits 4-hydroxy phenyl pyruvate dioxygenase which converts 4-hydroxyphenylpyruvate to homogentisic acid. This prevents accumulation of a toxic metabolite, fumarylacetoacetate. A combination of NTBC and dietary restriction have shown to prevent development of chronic liver disease, renal tubular damage, hepatocellular carcinoma, neurological manifestations, and avoid transplantation. ${ }^{15,16}$ United States and Canadian consensus group recommends periodic screening with liver imaging and AFP levels to detect early hepatocellular carcinoma. ${ }^{5}$

There is no radiological tool for screening as biochemical tests form the basis of imaging. However, in India, neonatal screening tests are not in place and diagnosis is often delayed. Radiologists can piece together constellation of findings in these cases and arrive at this unifying diagnosis. In addition, routine sonological/CT imaging is needed in these patients to screen for hepatocellular carcinoma screening.

\section{Conclusion}

Hereditary tyrosinemia type 1 is a rare disorder and rarely on list of differentials for a primary presentation of chronic liver disease in children. Combination of associated features of renal involvement and rickets should raise the suspicion of this disease. Early diagnosis is essential as early medical management can avoid hepatic and renal failure and prevent development of hepatocellular carcinoma. They also prevent liver transplantation in many patients. Genetic counseling and screening of siblings is recommended. A neonatal screening with serum and or/ urine succinylacetone levels are recommended.

\section{Conflict of Interest}

None declared. 


\section{References}

1 Orphanet. Tyrosinemia type 1 . https://www.orpha.net/ consor/cgi-bin/OC_Exp.php?Lng=GB\&Expert $=882$. Accessed on November 22, 2019

2 Mohamed S, Kambal MA, Al Jurayyan NA, et al. Tyrosinemia type 1: a rare and forgotten cause of reversible hypertrophic cardiomyopathy in infancy. BMC Res Notes 2013;6:362. Doi, 10.1186/1756-0500-6-362

3 Oh MS, Hwang G, Han S, et al. Sonographic growth charts for kidney length in Normal Korean children: a prospective observational study. J Korean Med Sci 2016;31(7):1089-1093

4 Udawat P, Gupta RK. Shambhavi, Sitaraman S. Tyrosinemia type 1: a case report and review of literature. Indian Journal of Medical Case Reports 2016;5(1):9-12

5 Chinsky JM, Singh R, Ficicioglu C, et al. Diagnosis and treatment of tyrosinemia type I: a US and Canadian consensus group review and recommendations. Genet Med 2017;19(12):1380

6 Mitchell GA, Grompe M, Lambert M, Tanguay RM, Hypertyrosinemia. In: Valle D, Beaudet AL, Vogelstein B, et al, eds. The Online Metabolic and Molecular Bases of Inherited Disease. New York, NY: McGraw-Hill; 2014

7 Weinberg AG, Mize CE, Worthen HG. The occurrence of hepatoma in the chronic form of hereditary tyrosinemia. J Pediatr 1976;88(3):434-438

8 van Spronsen FJ, Thomasse Y, Smit GP, et al. Hereditary tyrosinemia type I: a new clinical classification with difference in prognosis on dietary treatment. Hepatology 1994;20(5):1187-1191
9 Mitchell G, Larochelle J, Lambert M, et al. Neurologic crises in hereditary tyrosinemia. N Engl J Med 1990;322(7):432-437

10 Alobaidy H, Barkaoui E. Experience of a single center in NTBC use in management of hereditary tyrosinemia type I in Libya. Iran J Pediatr 2015;25(5):e3608

11 Solanki S, Dave K. Imaging spectrum of tyrosinemia: a rare metabolic disease entity. Poster presented at: EPOS, Congress: European Congress of Radiology; 2015, Poster No: C-0028 2015

12 Castilloux J, Laberge AM, Martin SR, Lallier M, Marchand V. "Silent" tyrosinemia presenting as hepatocellular carcinoma in a 10-year-old girl.J Pediatr Gastroenterol Nutr 2007;44(3):375-377

13 Sener RN. Brain magnetic resonance imaging in tyrosinemia. Acta Radiol 2005;46(6):618-620

14 Dubois J, Garel L, Patriquin H, et al. Imaging features of type 1 hereditary tyrosinemia: a review of 30 patients. Pediatr Radiol 1996;26(12):845-851

15 Masurel-Paulet A, Poggi-Bach J, Rolland MO, et al. NTBC treatment in tyrosinaemia type I: long-term outcome in French patients. J Inherit Metab Dis 2008;31(1):81-87

16 Bartlett DC, Lloyd C, McKiernan PJ, Newsome PN. Early nitisinone treatment reduces the need for liver transplantation in children with tyrosinaemia type 1 and improves post-transplant renal function. J Inherit Metab Dis 2014;37(5):745-752

17 Food and Drug Administration. Investigations operations manual 2015 Appendix C. Blood serum chemistry-normal values https://www.fda.gov/media/75935/download. Accessed on November 22, 2019 